\title{
Responses to tobacco control policies among youth
}

\section{A Crawford, G I Balch, R Mermelstein and the Tobacco Control Network Writing Group*}

\author{
See end of article for \\ authors' affiliations and \\ *members of the Tobacco \\ Control Network Writing \\ Group \\ Correspondence to: \\ Myra A Crawford, PhD \\ Division of Research, \\ University of Alabama at \\ Birmingham, School of \\ Medicine, Department of \\ Family and Community \\ Medicine, 930 South 20th \\ Street, Room 325 \\ Birmingham, AL 35205 \\ USA; mcrawf@fms.uab.edu \\ Received \\ 17 November 2000 \\ and revision requested \\ 20 March 2001. \\ Accepted \\ 12 October 200
}

Tobacco Control 2002;11:14-19

Objective: Explore adolescents' response to current and potential tobacco control policy issues.

Design: The 13 site Tobacco Control Network (TCN), sponsored by the Centers for Disease Control and Prevention, conducted 129 sex and ethnic homogeneous focus groups.

Participants: 785 white, African American, Asian American/Pacific Islander, American Indian, and Hispanic adolescents who were primarily smokers from rural, urban, and suburban locations across the USA.

Main outcome measures: Awareness, knowledge, opinions, and behaviour regarding laws and rules, prices, cigarette ingredients, and warning labels.

Results: Teenagers were generally familiar with laws and rules about access and possession for minors, but believed them ineffective. They were knowledgeable about prices, and reported that a sharp and sudden increase could lead them to adjust their smoking patterns but could also have negative consequences. They found a list of chemical names of cigarette ingredients largely meaningless, but believed that disclosing and publicising their common uses could be an effective deterrent, especially for those who were not yet smoking. They were aware of current warning labels, but considered them uninformative and irrelevant.

Conclusions: Understanding teenagers' attitudes and behaviours before implementing policies that will affect them will likely increase their effectiveness. Disclosing and publicising the chemical contents of cigarettes, and increasing prices quickly and sharply, are potentially effective areas for policy change to impact adolescent tobacco use.
M ost new smokers in the USA are adolescents. ${ }^{1}$ After two decades of decline, prevalence rates of adolescent smoking rose sharply in the 1990s, slowing somewhat at the end of the decade. ${ }^{1-3}$ In 2000, 24\% of 10th graders (ages $15-16$ years) and $31 \%$ of 12 th graders (ages $17-18$ years) reported smoking at least one cigarette during the past month. Daily smoking was reported by $14 \%$ of 10 th graders and $21 \%$ of 12 th graders. ${ }^{2}$

Recent legislation, rulings, and litigation have resulted in the formation of tobacco control policies aimed at reducing consumption among youth. In 1992, the US Congress enacted the Alcohol, Drug Abuse and Mental Health Administration Reorganization Act (P.L. 103-321), which includes the "Synar Amendment" (Section 1926) restricting youth access to tobacco and setting penalties for states that did not reduce illegal purchases by minors. In 1995, the US Food and Drug Administration ruled that it had jurisdiction over products containing nicotine, including provisions involving youth access, labelling, and advertising, and making the sale of cigarettes and smokeless tobacco to anyone under 18 years of age a federal violation. In 1998, after Congress failed to pass comprehensive tobacco control legislation (including a tax increase), a Master Settlement Agreement was reached between the tobacco industry and states which included restrictions on advertising and accessibility to youth. A non-profit organisation (the American Legacy Foundation) was also established, with one of its primary goals being to reduce youth tobacco use. States and communities began increasing activities to regulate the sale and consumption of tobacco by minors, in some cases penalising for possession.

Youth smoking is significantly lower where tobacco control laws are more aggressively enforced and where compliance is higher. ${ }^{4-6}$ No research has been conducted on how this reduction occurs among teenagers and what other effects such policies might produce.
The purpose of this study was to investigate how youth respond to the broader social and policy environment surrounding smoking. The Tobacco Control Network (TCN), a 13 site consortium of investigators from across the USA, was interested in learning more about youths' overall level of awareness and knowledge of tobacco related policies, and probing their reactions to: (1) potential price increases; (2) ingredients listings; and (3) current and proposed warning labels. A secondary interest was to explore whether those responses varied by sex and ethnicity.

The investigators decided that focus groups would be particularly well suited for this purpose. ${ }^{7-12}$ Focus groups offer opportunities for group interaction, spontaneity and openness, flexibility, peer support, descriptive depth, and for unanticipated issues to emerge.

\section{METHODS}

\section{Overview of design}

This study was a collaboration among the Office on Smoking and Health of the Centers for Disease Control and Prevention (CDC) and members of the TCN, scientists from 13 CDC funded prevention research centres across the USA. The multisite collaboration allowed access to a broad sample of ethnic groups and geographic diversity (urban, suburban, and rural areas) and enhanced the generalisability of the findings. Each site independently conducted recruitment, data collection, and analysis using a common protocol including interview guides, questionnaires, and coding schemes. Meetings, conference calls, and electronic discussions were used to coordinate the study elements across sites.

Abbreviations: CDC, Centers for Disease Control and Prevention; TCN, Tobacco Control Network 
Table 1 Study population by race, sex, and site

\begin{tabular}{|c|c|c|c|c|c|}
\hline \multirow[b]{2}{*}{ Race } & \multicolumn{3}{|l|}{ Sex } & \multirow{2}{*}{$\begin{array}{l}\text { Number of } \\
\text { groups }\end{array}$} & \multirow[b]{2}{*}{ Sites } \\
\hline & Males & Females & Mixed & & \\
\hline African American & 19 & 14 & 3 & 36 & $\begin{array}{l}\text { Alabama, Maryland, Missouri, New York, North Carolina, } \\
\text { South Carolina }\end{array}$ \\
\hline American Indian & 4 & 6 & & 10 & New Mexico, Oklahoma \\
\hline $\begin{array}{l}\text { Asian American/ Pacific } \\
\text { Islander* }\end{array}$ & 5 & 5 & & 10 & Washington \\
\hline Hispanic & 3 & 2 & & 5 & New Mexico \\
\hline White & 34 & 34 & & 68 & $\begin{array}{l}\text { Alabama, Illinois, Maryland, Minnesota, Missouri, North } \\
\text { Carolina, South Carolina, Texas, West Virginia }\end{array}$ \\
\hline Total & 65 & 61 & 3 & 129 & Total number of sites $=13$ \\
\hline
\end{tabular}

* Because of the small number of Asian American Islander participants ( $n=40)$, they were not stratified by individual ethnic group, which included Samoans, Vietnamese, and Mien.

\section{Table 2 Current and potential warning labels}

Current US Surgeon General's warnings
- Cigarette smoke contains carbon monoxide
- Smoking by pregnant women may result in fetal injury,
premature birth, and low birth weight
- Smoking causes lung cancer, heart disease, emphysema, and
may complicate pregnancy
- Quitting smoking now greatly reduces risks to your health
Potential warnings
- If you think smoking is cool you are dead wrong
- Smoking reduces your athletic ability
- Smoking can kill you
- Smoking is addictive
- SOO OOO Americans die each year because of smoking
- Your smoking can harm others
- Tobacco smoke pollutes the air and is a health hazard
- Tobacco smoke can harm children
- Smoking when pregnant harms your baby

\section{Study population}

In 1998, 129 focus groups were conducted with 785 teenagers at the 13 TCN sites (table 1). The groups included males and females from five ethnic groups (white, African American, American Indian, Asian American/Pacific Islander, and Hispanic), who were either current smokers (that is, had smoked during the past 30 days) or experimenters (that is, had tried smoking in the past, even one puff). Of those 785 teens, $649(82.7 \%)$ reported that they had smoked within the last 30 days.

Of the 129 groups, 68 (52.7\%) were comprised of white participants. The remainder were composed of African Americans $(\mathrm{n}=36 ; 27.9 \%)$, American Indians $(\mathrm{n}=10 ; 7.75 \%)$, Asian American/Pacific Islanders $(\mathrm{n}=10 ; 7.75 \%)$, and Hispanics $(\mathrm{n}=5 ; 3.9 \%)$. Participants ranged in age from $12-19$ years (mean age 15.5 years). Stratified by sex, 65 groups were composed of males $(50.4 \%)$; 61 , females $(47.3 \%)$; three, mixed sex $(2.3 \%)$. They were evenly distributed in terms of locale (that is, rural, urban, and suburban).

\section{Recruitment}

Participants were recruited primarily through local high schools, community organisations, and, at one site, a market research firm. ${ }^{13}$ Recruitment focused on current smokers to ensure exposure to tobacco control policies. An attempt was made to sample youth from all socioeconomic levels (from affluent college bound students to inner city and tribal school students living in poverty) and from communities with varying levels of policy enforcement. Active parental consent was obtained.

Participants completed questionnaires about their experiences with smoking, how and where they obtained cigarettes, and whether they had ever "gotten in trouble" for smoking. Almost half (43\%) reported smoking on 20 or more days of the last 30 days. The percentage who had ever smoked $(88.5 \%$ overall) varied by ethnicity: whites $95 \%$, African Americans 86.6\%, Hispanics 97.3\%, American Indians 100\%, and Asian American/Pacific Islanders 53\%. Many of the participants (471; 60\%) had purchased cigarettes for themselves, typically from a convenience store (69\%). Of those reporting they had ever smoked, $36 \%$ indicated they had gotten in trouble with parents, school officials, or other authority figures for smoking cigarettes.

\section{Focus groups}

Focus group interviews were conducted among groups of 6-12 teens by trained moderators, typically matched to each group by sex and ethnicity. Interviews were conducted at schools, community centres, and a market research facility. Participants were paid in cash (typically \$20) or coupons (for merchandise, pizza, or movies), depending on site.

All sites used a common interview guide developed by the investigators. Interviews typically lasted one hour. The core content areas included: (1) awareness, understanding of, and reactions to current tobacco policies; (2) awareness and understanding of current warning labels and reactions to potential ones; (3) understanding of, and reactions to, chemical ingredients in tobacco and from smoke; (4) awareness of tobacco pricing and reactions to alternative higher prices; and (5) perceived effectiveness of current and potential policies.

Structured exercises included a discussion of warning labels (table 2); chemical ingredients with and without their common uses (table 3); an activity used to gauge the price at which participants would no longer buy cigarettes; and a list of current and potential (hypothetical) policies (table 4). Sites used various techniques to stimulate discussion and "measure" group opinion, including ranking, voting, and constant sum allocation. Moderators probed on whether and how various policies decreased or increased the appeal of cigarettes, whether and how they affected teens' ability to obtain and smoke cigarettes, and how they felt about enforcement.

\section{Data coding and management process}

All interviews were audiotaped and transcribed. Transcripts were typically reviewed against the tapes for accuracy. Each transcript was coded independently by two trained coders, then reconciled by a third, based on a coding scheme ("codebook") developed by the investigators to reflect the core content areas of the study. Once finalised, the data (that is, coded transcripts) were entered into QSR-NUD*IST, qualitative data analysis software.

\section{Data analysis process}

Using a common protocol for interviewing and coding permitted cross site examination of each of the core content 
Table 3 Sample chemical ingredients with common uses

\begin{tabular}{ll}
\hline Ingredient & Common use \\
\hline Acetone & Paint stripper \\
Ammonia & Floor cleaner \\
Aresenic & Pesticide \\
Butane & Lighter fluid \\
Cadmium & Car batteries \\
DDT & Insecticide \\
Hydrogen cyanide & Poison \\
Toluene & Industrial solvent \\
\hline DDT, dichlorodiphenyltrichloroethane
\end{tabular}

Table 4 Potential policies to deter youth smoking

- No smoking in open air facilities such as ball parks, stadiums, and concerts

- No tobacco advertising within 1000 feet $(300 \mathrm{~m})$ of a school

- No smoking anywhere open to the public

- Legal age for purchase of cigarettes (age 18 years)

- Make anyone who sells or gives cigarettes to minors pay a fine, including parents, other adults, and kids

- Take away a store's licence to sell cigarettes if they are caught selling to minors three or more times

- Make minors pay a fine for possession of tobacco

- Make parents of minors pay a fine for their child's possession of tobacco

- Reward non-smoking kids/teens with special discounts at movies, stores, etc

- Ban advertising for cigarettes in magazines that lots of kids/teens read

- Charge $\$ 6.00$ per pack of cigarettes

- Put stronger warning labels on all packs of cigarettes and all cigarette advertisements

- List all of the ingredients in cigarettes

- Require that all cigarette packaging and advertising be only in black and white

- Prohibit all advertising for cigarettes

- Advertise everywhere how positive it is for kids/teens to be smoke-free

areas (awareness, pricing, ingredients, and warnings). Matrices were generated by the indexing of codes in NUD*IST. Each site initially examined its own data and prepared a summary of the main findings by content area. Common themes emerged. A measure of saliency (a subjective weight indicating the relative strength and consistency of responses independent of frequency) was assigned to each theme. Representative quotes were captured.

The results from each site's analyses were forwarded to one site (Birmingham) to be combined into thematic lists and saliency models. The many similarities and few differences across sites were readily apparent. A summary of overall findings was drafted and reconfirmed by the investigators. Key findings across all 13 sites are reported here.

\section{FINDINGS}

\section{Awareness and knowledge of policies and rules}

When asked "what kinds of rules or laws about smoking have you heard or seen lately?" the teens indicated that they were aware of policies in place in their communities. They knew it was illegal for stores to sell tobacco to anyone under age 18, and that stores were required to demand proof of age before sale. Participants from communities with ordinances about possession or use by minors were usually aware of those ordinances; however, the depth of their understanding varied. Some thought that it was illegal for any person (that is, a private individual) to distribute cigarettes to a minor, whether in a retail establishment or not. Some had an inflated sense of the penalties (for example, $\$ 500$ fine for first offense rather than the actual \$25). The correct penalties and process of enforcement were usually known just to the few who had run foul of them.

Almost all participants were aware that clean indoor air rules exist, but were not necessarily aware of specific laws in their own communities. Participants were less aware of tobacco policy issues that did not directly affect them. Despite extensive coverage in the press at the time, some were not even aware of the high profile lawsuits pending against tobacco companies.

Participants shared a general view that anti-smoking policies are beneficial for younger children and non-smokers, but not for teens who are already smoking. They felt protective toward their non-smoking counterparts, but believed that those who were already smoking would continue, especially if addicted. A typical response came from a suburban Hispanic male when he said, "If we were younger maybe, but unfortunately it's too late." Most agreed that age 18, as a legal age for smoking, was too high; many thought it should be lowered to age 16 ("when you can drive"). They considered clean indoor air policies a matter of common courtesy and minor inconvenience. Most said that they respected and complied with policies directed at all smokers (such as clean indoor air), but not policies directed solely at minors (such as age restrictions).

They typically found enforcement of policies weak, inconsistent, and inconsequential. "Any store that says "under 18 we card' usually doesn't card you or they'll accept any ID, even if it's not correct," said an urban white male. A rural white female said, "Cops don't care. They may tell you to put it out but they don't make you pay the fine." They felt those who are addicted could — and would-always find a way to circumvent rules or laws designed to protect them, and that current restrictions on tobacco access were a mild inconvenience, nothing to fear. "People who are on cigarettes are just like people on crack - they'll do anything for their cigarettes," said a rural black female. A suburban white female said, "There's always someone out there who will buy them for you."

Participants described how they could easily acquire and smoke cigarettes. They were usually able to buy cigarettes for themselves or get someone older to buy for them. Many knew which stores or clerks in their communities would allow them to buy. Some had false identification. To avoid being penalised for smoking, they simply did not smoke openly or where it would be easy to get caught. Rather, they smoked in cars, homes or other inconspicuous locations, believing it was "nobody's business" as long as it was not in public. Almost none thought that anti-smoking policies heightened the appeal of tobacco to teens as "forbidden". None considered current policies a valid reason to consider quitting or reducing smoking. No clear ethnic or sex differences about knowledge of policies and rules emerged.

\section{Warning labels}

Most participants were aware of the US Surgeon General's current warning labels, but reported that they did not find them informative, impressive, or relevant. When asked to recall the warnings, they typically mentioned disease and pregnancy. Most teens considered these warnings personally irrelevant, however, because they were neither pregnant nor "old enough" to contract smoking related diseases. "I mean it's a health risk, but I'm gonna die sometime," said a rural black female. A native American female said, "I don't really think about that [the health consequences] that much. I don't think about the warnings 'cause it doesn't matter right now." Further, they believed they would be able to quit smoking before they became old, sick or pregnant. Many did not recall the warning about carbon monoxide at all.

Participants described the current warning labels as "vague", "stale", and "worn out". They indicated that teens 
"don't take them seriously" and characterised the wording as "too mild", giving the impression that the chances of actually suffering consequences from smoking are small.

The teens suggested that warnings should be direct, realistic, factual, and strong. They wanted clear information with no room for doubt. "That don't even look threatening," said an urban white male. "You need a lot of exclamation points, 'SMOKING WILL KILL YOU!!!' When it says it 'may' it sounds like you a have a 50-50 chance so why not risk it?" They thought that such messages should be placed where they would be more noticeable, even graphic, and should provide information on the short term health effects of smoking. For example, a suburban white female said, "I don't want my teeth to be yellow. I don't want to smell and I mean that's what's important to teenagers." Another said, "Don't just say it, show it." They believed that warning labels, like other policies, would be most effective in deterring younger children who had not started smoking, but would be ineffective for those already smoking, especially if addicted. The only consensus about the proposed warning labels (table 2) was that the statement "if you think smoking is cool you're dead wrong" was "stupid". Reactions to other warnings varied but, overall, participants across all sites felt that warning labels alone would be ineffective in reducing smoking among youth.

\section{Ingredients}

Few participants could name ingredients or chemicals that are added to cigarettes or that occur as a byproduct of burning tobacco. Some had misinformation about contents-for example, fibreglass in cigarettes, asbestos in filters. While many felt that tobacco products advertised as "additive free" or "all natural" were a marketing ploy, a few believed they were less harmful than "regular" cigarettes.

When moderators displayed a sample list of chemicals found in cigarettes and smoke, most participants did not immediately recognise them or associate them with cigarettes. When, however, moderators revealed the common uses of those chemicals (such as pesticide, wood stripper, and nail polish remover), the response across all groups was dramatic.

Most participants initially expressed shock or surprise. In some groups, conversation came to a standstill. Many expressed disgust and outrage about the new information and the fact that it is not widely known. Some wondered how these chemicals could be allowed in cigarettes and how their presence could be hidden from the public. They were angry about this apparent deception. "How can they DO that? How can the government let tobacco companies just do that to people?" asked an urban white male. A rural white female said, "You look at that list and you wonder how many lives would have been saved if that came out sooner." They urged that the list of chemicals and common uses be widely publicised and, by law, disclosed and displayed on every cigarette package and wherever cigarettes are sold. They felt presenting the names of chemicals alone would be meaningless simply because "most people don't know what they are".

After the initial reaction subsided, some participants rationalised that the chemicals must be present in amounts "too small to do much harm" or that "there are harmful chemicals in everything people use" and "you're going to die anyway". A few stated they would substitute or prefer marijuana because "it's natural". Many agreed that the information about ingredients might deter initiation and might have deterred them from smoking, but probably would not make addicted smokers quit. A native American female said, "I'm not gonna quit 'cause I know what's in it, but if I would have known what was in it before I started smoking I probably wouldn't have started." "It'd keep younger kids from starting, but by the time you get to be a teenager, you're like, you don't care. You think you're invincible," said a rural white male. Some remained impressed enough to say that this new information may cause them to smoke less or consider quitting.
"Lighter fluid, floor cleaning, pesticide, oh come on! Chemicals found in car batteries? You be getting, I mean, I didn't know I was doin' all this to my body. Forget it, I ain't smokin' no more," said a rural black male.

Some participants wanted to continue discussing this topic even after the time came to move on. Some wanted more information to take with them. Discussing ingredients, especially when using the more negatively charged word "chemicals", created a teachable moment. This was true for all ethnic and sex groups across the 13 sites.

\section{Price}

Teens were asked several questions about price, including "How much do you pay for cigarettes? How much would you pay? Where do you get the money?" They were familiar with cigarette prices in their area and knew where to find the best deals. Many shopped around and often passed information about sale prices or promotions (that is, buy one get one free) on to other teens. Some younger participants noted that, because of their age, they were forced to buy cigarettes wherever they could and not necessarily where they were cheapest.

The price per pack of cigarettes (averaging $\$ 2-£ 3$ at the time) was used as a starting point for discussion. Participants offered a variety of ideas about how a price increase would affect their smoking behaviour. The duration, richness, and intensity of the discussions clearly indicated that price matters to teens. Some ideas for coping with price increases were based on experience (for example, asking others to buy, stealing), while others were expressions of naiveté (for example, starting a tobacco farm) or bravado (for example, hijacking a cigarette truck).

Some ideas were consistent with the policy objective of reducing cigarette consumption among youth. Participants volunteered that they might buy more single cigarettes and fewer packs, share cigarettes less often, chew gum, smoke less, stop buying, or even quit smoking altogether. They suggested that they might buy and split packs with others, borrow ("bum") more, roll their own, get a job, or work more hours at a current job. While some said they would be unlikely to compensate for a substantial price increase, others were determined to "find a way" to continue smoking.

Unintended negative consequences included "stocking up" and selling cigarettes at a profit; buying "black market" cigarettes; working at a store that sells cigarettes; stealing cigarettes from stores or family members; and using other forms of tobacco or other substances, such as nicotine replacement products, alcohol, or marijuana. A small subset stated they would sell marijuana to support their smoking habit. Others stated they would skip meals or reduce spending on other items such as clothes or entertainment in order to afford cigarettes. Some indicated that their parents would provide enough money for them to continue to buy cigarettes, even at increased rates.

For price increases to affect their smoking practices, the teens agreed that they needed to be sudden and substantial. The cutoff point at which most teens said that they would quit buying varied by economic landscape. While some more affluent urban and suburban teens said they would pay up to $\$ 10$ per pack, most agreed that they would stop buying at $\$ 6$ per pack (three times the current price). Rural teens typically felt they would not buy cigarettes at $\$ 5$ per pack, or that it would be much harder for them to do so. Some less affluent inner city teens put the cutoff point even lower. No ethnic or sex differences emerged concerning price.

\section{Response to potential policies}

Following a discussion of warning labels, ingredients, and price as specific content areas, participants were exposed to 16 actual or potential policies to deter youth smoking (table 4). These included restrictions for the general public and those 
applying only to minors; restrictions related to warning labels, ingredients, and price; and restrictions related to advertising, access, and penalties.

In every focus group in each of the 13 sites, regardless of the method of presentation, only two policies consistently stimulated the youth to stop and think about their smoking: a large price increase, and listing ingredients with common uses. Again, no clear ethnic or sex differences emerged.

\section{DISCUSSION}

Teens across the nation expressed similar views about policies, warning labels, ingredients, and price with no clear ethnic or sex differences emerging among them. Previous research shows a lack of consensus about tobacco policies among adults. ${ }^{6}$ Also consistent with published research, ${ }^{14-22}$ teens in this study found access restrictions to be poorly enforced and easily circumvented, and considered current warning labels uninformative and personally irrelevant.

Learning about the chemicals to which they were exposed while smoking, when given their common uses, generated a teachable moment about the risks of tobacco use. It made the teens feel uncomfortable about smoking, and prompted them to think about changing their behaviour. Also consistent with prior econometric research, ${ }^{23}$ the prospect of dramatic and sudden escalation in prices stimulated thoughts about changing behaviour. These key findings suggest intriguing areas for further research and guidance for the formulation of future policies.

\section{Unintended consequences}

The teens discussed potential unintended consequences that may arise from the implementation of new or more stringent smoking restrictions aimed specifically at youth-that is, price increases resulting in more illegal sales, stealing, or an increase in other drug use. Care in over-analysing these responses is suggested; while they raise concerns, econometric studies do not support this result. ${ }^{24}$

There was no indication that tighter restrictions on cigarette smoking would make smoking more appealing to teens. None of the suggested policies increased the appeal of cigarettes as "forbidden". Some of these policies may prevent smoking initiation among younger children, as these teens commonly suggested. Qualitative research with younger children may merit consideration.

\section{Conclusions}

Focus groups offer rich insights and are an effective method for generating hypotheses about what and how youth think and feel. They are not necessarily reliable predictors of behaviour. However, because these findings about youth tobacco use were consistent across a large number of sites, and because they corroborate prior research, they do merit serious consideration. Publicising the chemical contents of cigarettes and increasing prices quickly and sharply suggest important areas for policy change.

The environments of tobacco control and youth culture continue to evolve. It is important to explore teens' cognitive, attitudinal, normative, and behavioural environments. ${ }^{25} 26$ Seeking to understand teens' perspectives before formulating and implementing polices aimed at protecting them will increase the likelihood that they will be effective and result in positive outcomes.

\section{ACKNOWLEDGMENTS}

Special appreciation is expressed to Jean Marie White of the University of Alabama at Birmingham for her assistance in preparing this paper. The 13 participating sites were: the University of Alabama at Birmingham; the University of Illinois at Chicago; Columbia University; Johns Hopkins University; St Louis University; University of Minnesota; University of North Carolina, Chapel Hill; University of South Carolina, Columbia; University of Texas, Houston; University of

\section{What this paper adds}

Much is known about the rates at which teens use tobacco. Where tobacco control laws are aggressively enforced and compliance is high, it has also been observed that youth smoking is lower. Teens have demonstrated that they are aware of the risks of tobacco use, but do not feel that they are personally at risk. Little is known about why teens smoke, and why they respond or do not respond to policies that affect their tobacco use.

This study of 129 focus groups, conducted over 13 sites in the USA, revealed that almost to a person, the 785 teens from five ethnic groups who participated felt that publicising the chemical contents of cigarettes and byproducts of smoke and quickly and sharply increasing prices would be the areas of policy action that would most effectively change their tobacco use behaviour.

New Mexico; University of Washington; West Virginia University; and University of Oklahoma, Oklahoma City. The Coordinating Center was at UIC. This study was supported by the Office on Smoking and Health, Centers for Disease Control and Prevention for the Prevention Centers Tobacco Network Project.

\section{Authors' affiliations}

M A Crawford, University of Alabama at Birmingham, School of Medicine, Department of Family and Community Medicine, 930 South 20th Street, Room 325, Birmingham, AL 35205 USA;

mcrawf@fms.uab.edu

G Balch, R Mermelstein, University of Illinois, Chicago, Health and Research Policy Centers, 850 W. Jackson Boulevard, Suite 400

Chicago, IL 60607, USA; gbalch@uic.edu; robinm@uic.edu

*The Tobacco Control Network Writing Group members for this paper are: Office on Smoking and Health, Centers for Disease Control and Prevention-Beverly Kingsley, PhD; Columbia University-Edward Healton, MD; Johns Hopkins University-Cheryl Alexander, PhD, Joel Gittelsohn, PhD; University of Minnesota-Jean Forster, PhD; University of

New Mexico-Sally M Davis, PhD, Peg Allen, MPH; University of North Carolina-Sandra Headen, PhD, Tim McGloin, MSPH; University of Oklahoma-Vicki Cleaver, EdD; St Louis University-Douglas Luke, PhD; University of South Carolina, Columbia-John R Ureda, DrPH, Carol E Rheaume, MSPH; University of Texas, Houston-Steven Kelder, PhD; University of Washington-Clarence Spigner, DrPH; West Virginia University-Robert H Anderson, MA, CHES.

\section{REFERENCES}

1 US Department of Health and Human Services. Preventing tobacco use among young people. A report of the Surgeon General, 1994. Atlanta, Georgia: Public Health Service, Centers for Disease Control and Prevention, Office on Smoking and Health, 1994. (US Government Printing Office Publication No S/N 017-001-00491-0.)

2 Johnston LD, O'Malley PM, Bachman JG. Monitoring the Future national survey results on drug use, 1975-2000. Volume I: Secondary school students. (NIH Publication No. 01-4924). Bethesda, Maryland: National Institute on Drug Abuse, 2001, c. 492 pp.

3 Lynch B, Bonnie R, eds. Growing up tobacco free: preventing nicotine addiction in children and youths. Washington DC: National Academy Press, 1994.

4 Wakefield MA, Chaloupka FJ. The economics of global tobacco control BM 2000;321:358-61.

5 Forster JL, Murray DM, Wolfson M, et al. The effects of community policies to reduce youth access to tobacco. Am J Public Health 1998:88: 1193-8.

6 Jacobson PD, Wasserman J. Tobacco control laws: implementation and enforcement. Rand: Santa Monica, California, 1997.

7 Asbury J. Overview of focus group research. Qualitative Health Research 1995:5:414-20.

8 Goldman AE, McDonald SS. The group depth interview: principles and practices. Englewood Cliffs, New Jersey: Prentice-Hall, 1987

9 Krueger RA. Focus groups: a practical guide for applied research, 2nd ed. Newbury Park, California: Sage Publications, 1994.

10 Krueger RA. The future of focus groups. Qualitative Health Research 1995;5:524-30.

11 Mertens DM. Research methods in education and psychology: integrating diversity with quantitative and qualitative approaches. Thousand Oaks, California: Sage Publications, 1998.

12 Morgan DL, Krueger RA. The focus group kit. Thousand Oaks, California: Sage, 1998. 
13 McCormick LK, Crawford, MA, Anderson RH, et al. Recruiting adolescents into qualitative tobacco research studies: experiences and lessons learned. Journal of School Health 1999;69(3):95-9.

14 Downey L, Gardiner JA. Reducing youth access to tobacco: a partial inventory of state initiatives. Chicago, Illinois: University of Illinois at Chicago Office of Social Science Research, 1996.

15 Feighery $\mathbf{E}$, Altmann D, Shaffer $G$. The effects of combining education and enforcement to reduce tobacco sales to minors: a study of four northern California communities. JAMA 1991;266:3168-71.

16 Hinds $M$. Impact of a local ordinance banning tobacco sales to minors. Public Health Reports 1992;107;355-8.

17 Jason L, Ji P, Anes M, et al. Active enforcement of cigarette control laws in the prevention of cigarette sales to minors. JAMA 1991;266:3159_ 61.

18 Jason L, Billows W, Schnopp-Wyatt D, et al. Long-term findings from Woodridge in reducing the illegal sales of cigarettes to older minors. Evaluation and the Health Professions 1996;19:3-13.

19 Jason L, Billows W, Schnopp-Wyatt D, et al. Reducing the illegal sales of cigarettes to minors: analysis of alternative enforcement schedules, Journal of Applied Behavior Analysis 1996;29:333-44.
20 Radecki TE, Zdunich CD. Tobacco sales to minors in 97 U.S. and Canadian communities. Tobacco Control 1993;2:300-5.

21 Williams R, Hersey J, Mowery P, et al. Design of inspection surveys for vendor compliance with restrictions on tobacco sales to minors. Atlanta, Georgia: Battelle, 1994.

22 Krugman DM, Fox RJ, Fischer PM. Do cigarette warnings warn? Understanding what it will take to develop more effective warnings. Journal of Communication 1999;4:95-104.

23 Chaloupka FG. The impact of proposed cigarette price increases. Policy Analysis, No. 9, Health Science Analysis Project. Washington DC: The Advocacy Institute, 1998.

24 Chaloupka FJ, Pacula RL, Farrelly MC, et al. Do higher cigarette prices encourage youth to use marijuana? NBER Working Paper No. W6939 Cambridge, Massachusetts: National Bureau of Econometric Research, February 1999, JEL No. 118

25 Crawford M. CDC Tobacco Control Network Writing Group. Cigarette smoking and adolescents: messages they see and hear. Public Health Reports 2001; suppl 1(116):203-15.

26 Luke D, Allen P, Arian $G$, et al. Teens' images of smoking and smokers. Public Health Reports 2001; suppl 1(116):194-202.

\section{FROM THE JECH GALLERY}

\section{Water, tobacco, and global inequalities}

T

hese photographs are used to illustrate the public health impact of lack of water

and global inequalities. Southern Africa experienced one of the worst droughts in his tory in the early 1990s. For Mozambique, one of the world's poorest countries and at the time devastated by the effects of a US and South African backed guerrilla war the impact was immense. The first photo shows the Cahora Bassa dam (fig 1). This picture was taken in 1992 and shows the dam to be nearly empty. The water level should have been at the top edge of the distant wall. During the drought of 1991-1992 hundreds of thousands of Mozambicans died as a consequence of lack of water. It is depressing to realise that similar numbers have lost their lives recently because of floods. Just two months ago the Cahora Bassa dam was over flowing; two gates were opened resulting in the flooding of villages down stream with the consequent loss of homes and livelihood. Dur-

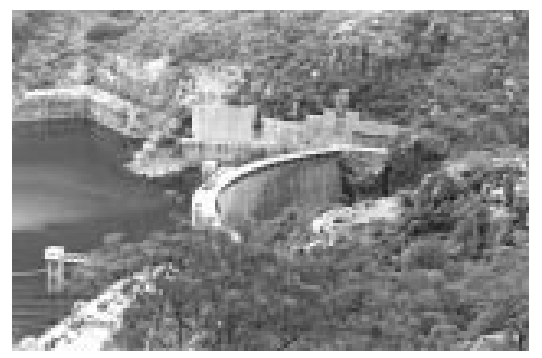

Figure 1 ing the drought obtaining water from whatever means was the most important daily preoccupation for everyone living in Mozambique (fig 2). Throughout the two years that I lived and worked in central Mozambique I saw trees collapse because of the drought (fig 3) and I never saw maize grow successfully. I did however see fields full of healthy growing tobacco on a multinational owned tobacco farm. Figure 4 shows tobacco drying in one of the barns of the tobacco farm.

The most appalling image I have in my mind is of poor Mozambicans grappling on hands and knees in the dust and dirt trying to pick up individual kernels of corn that had fallen from the backs of aid lorries with slogans such as "Jesus Alive" on their sides. Behind them were the green fields of growing tobacco and passing them also on the track the tankers of water being imported to grow the deadly weed.

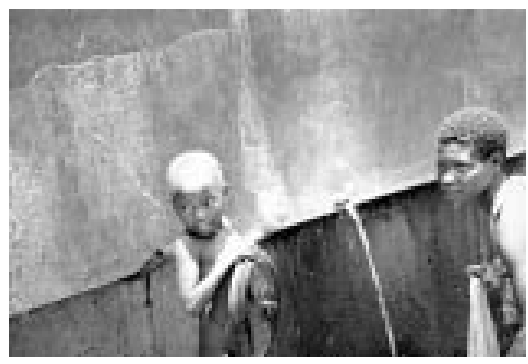

Figure 2

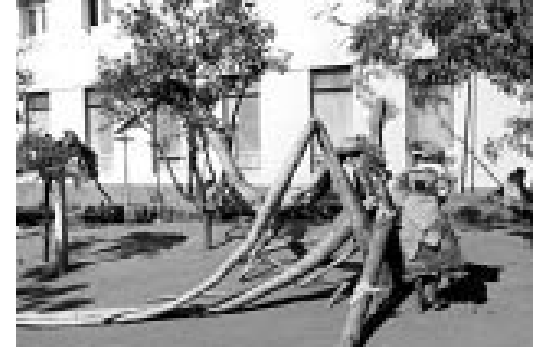

Figure 3

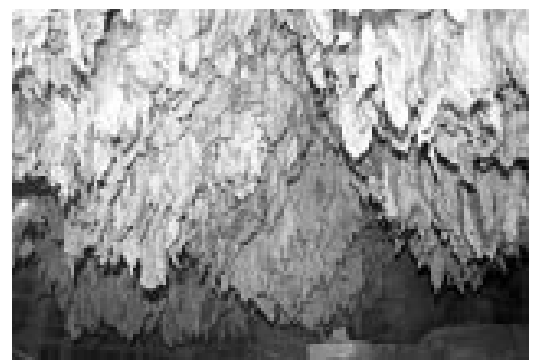

Figure 4

Debbie Lawlor

Department of Social Medicine, University of Bristol, Canynge Hall, Whiteladies Road, Bristol BS8 2PR, UK

Correspondence to: Dr Lawlor (D.A.Lawlor@bristol.ac.uk)

This article is reproduced in full with permission from J Epidemiol Community Health 2001,55:852. 